\title{
ARTICLE
}

\section{Nondestructive Analysis of the Ancient Egyptian Vitreous Relics by Neutron}

\author{
Shigeo YOSHIDA ${ }^{1 *}$, Kyoko YAMAHANA ${ }^{1}$, Hideaki MATSUE$^{2}$ and Isao Murata ${ }^{3}$ \\ ${ }^{I}$ Tokai University, Hiratsuka, Kanagawa 259-1292, Japan \\ ${ }^{2}$ Japan Atomic Energy Agency, Tokai-mura, Naka-gun, Ibaraki 319-1195, Japan \\ ${ }^{3}$ Osaka University, Suita, Osaka 565-0871, Japan
}

\begin{abstract}
The prompt gamma activation analysis (PGA) was carried out with thermal neutrons from the T1-4-1 beam port of JRR-3 facility in Japan Atomic Energy Agency (JAEA). Some nuclides were identified by photo peaks in the measured pulse height spectra of the ancient Egyptian vitreous relics and the element content ratio was quantified from the peak area net count ratio. We have preliminarily made clear their archaeological characteristics including the age of the antiquity, manufacturing method, trade route and so on.
\end{abstract}

\section{KEYWORDS: prompt gamma activation analysis, JRR-3, the ancient Egyptian vitreous relics, archaeology}

\section{Introduction}

Ultimate analysis by a general chemical technique requires sampling of a small part of the analysis sample and preprocessing such as powdering or dissolution. Particularly, nondestructive analysis becomes important for archaeological historical materials such as precious excavated relics. The prompt gamma activation analysis (PGA) with a neutron beam is a simultaneous multi-elements analysis which can be performed nondestructively. It becomes very effective for nondestructive analysis of the archaeology samples, because the residual radioactivity is infinitesimal after the irradiation as the incident neutron flux is quite low $\left(\sim 10^{8} \mathrm{n} / \mathrm{cm}^{2} \mathrm{sec}\right)$.

Relics which are a "real evidence" excavated from the ground possess important information, to achieve the archaeological purpose that rebuild the history of the human being by restoring their past activities and lives. Therefore, from the limited amount of resources, it is inevitable to extract valuable information as much as possible. Archeological approaches from the standpoint of the type and art history from the appearance of the relics are being carried out normally. However, recently analysis of elements constituting themselves becomes quite crucial, because the leading edge technology of the natural science (nuclear engineering) enabled it even nondestructively ${ }^{1-3)}$.

A lot of ceramics, called faience, made with materials including quartz were excavated from ancient Egyptian remains. The faience was made by firing green body which was a mixture of stone or sand as main materials including a lot of quartz $\left(\mathrm{SiO}_{2}\right)$ and a small amount of lime $(\mathrm{CaO})$ and alkali salt $\left(\mathrm{Na}_{2} \mathrm{O}\right.$ or $\left.\mathrm{K}_{2} \mathrm{O}\right)$ as glaze. In addition, coloring agents are mixed, which include copper ore $(\mathrm{CuO})$ or cobalt (Co) to color in blue, lead $(\mathrm{Pb})$ or antimony $(\mathrm{Sb})$ to color in yellow, iron oxide $\left(\mathrm{Fe}_{2} \mathrm{O}_{3}\right)$ or red copper $\left(\mathrm{Cu}_{2} \mathrm{O}\right)$ to color in red. Namely, the faience can be produced from raw materials having the same composition as glass by a production procedure of ceramics ${ }^{4), 5)}$.

*Corresponding Author, E-mail: neutron@keyaki.cc.u-tokai.ac.jp (C) Atomic Energy Society of Japan
The purpose of this study is in the following. The abundance of elements contained as main elements and/or trace elements are identified in ancient Egyptian vitreous relics (faience) and the sand around the excavation place. From the correlation of the both elemental contents, the characteristics concerning the age and location of them are investigated ${ }^{7-10}$. From the result, we investigate whether we can estimate the production and consuming areas of the relics and the trade routes connecting each area.

\section{Experiments}

The analysis has been performed by the thermal neutron prompt gamma activation analytical technique, using the prompt gamma activation analyzer which consisted of an Hp-Ge detector and a BGO detector, in the T1-4-1 beam port of JRR-3 nuclear reactor institution in Japan Atomic Energy

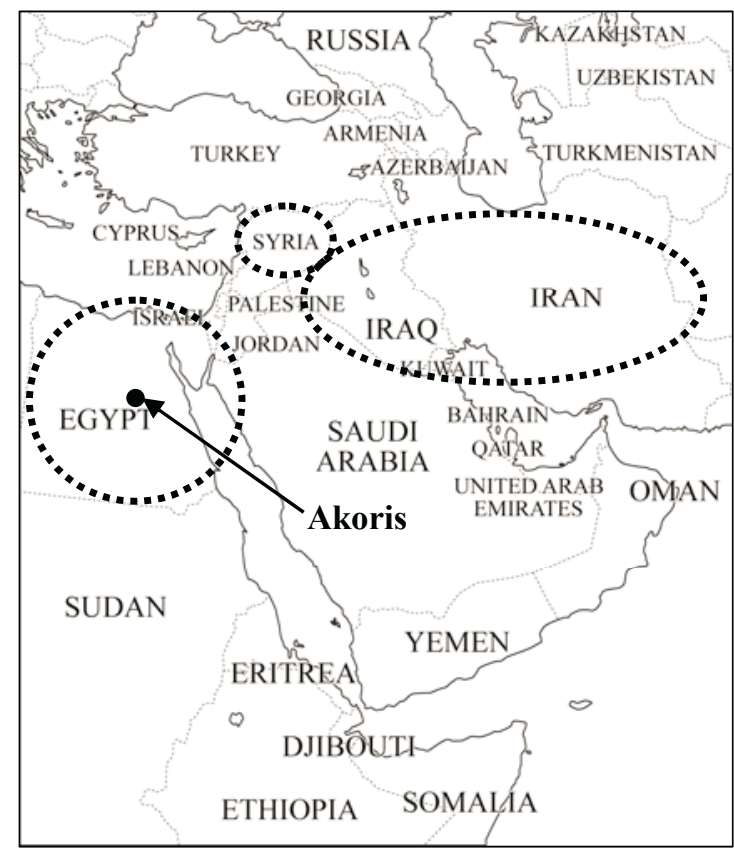

Fig. 1 Sampling areas 
Agency $(\mathrm{JAEA})^{11)}$. Samples analyzed were 63 samples of faience excavated at Akoris located in the Nile central part basin and 48 sand and rock samples taken in Egypt and neighboring West Asia. Their elemental composition was analyzed qualitatively and quantitatively, and the results were compared with each other. The sampling areas of the analysis samples were shown in Fig.1. The sample size was $5 \mathrm{~cm} \times 5 \mathrm{~cm}$ at maximum and less than $1 \mathrm{~cm}$ in thickness, they were sealed up with an FEP film and fixed on the central part of the sample folder in the irradiation chamber. The irradiations were performed for 3,000-5,000 seconds per one sample, keeping in helium gas atmosphere to prevent emission of prompt gamma-rays from nitrogen in the air through nuclear reactions induced by thermal neutrons. The beam size is about $2 \mathrm{~cm} \times 2 \mathrm{~cm}$ at the sample position and the thermal neutron flux intensity is $1.6 \times 10^{8}\left(\mathrm{n} / \mathrm{cm}^{2} \cdot \mathrm{sec}\right)$.

\section{Analysis}

Table 1 summarizes gamma-ray peaks energy (keV) measured and their production cross sections (b) for 18 elements, taking into account disturbing gamma-rays ${ }^{10)}$. In the table, the number of samples are also listed in the spectrum of which each gamma-ray was detected. As for dysprosium (Dy) and magnesium $(\mathrm{Mg})$, there are few samples detected in the sand and faience, while as for copper $(\mathrm{Cu})$ and sodium $(\mathrm{Na})$, there are few for the former in the sand and are few for the latter in the faience. This means it is

Table 1 Detected gamma-ray

\begin{tabular}{|c|c|c|c|c|c|}
\hline \multicolumn{3}{|c|}{$\begin{array}{c}\text { Detected gamma-ray peak energies and } \\
\text { their production cross sections }\end{array}$} & \multicolumn{2}{c|}{$\begin{array}{c}\text { Number of the detections } \\
\text { in the total number of samples }\end{array}$} \\
\hline A & Element & E $_{\gamma}(\mathrm{keV})$ & $\sigma_{\gamma}$ (b) & Sand & Faience \\
\hline 1 & H & 2223.248 & 0.3326 & 46 & 63 \\
\hline 10 & B & 477.595 & 716 & 48 & 63 \\
\hline 23 & Na & 874.389 & 0.076 & 25 & 61 \\
\hline 24 & Mg & 2828.172 & 0.024 & 16 & 4 \\
\hline 27 & Al & 1778.92 & 0.232 & 46 & 63 \\
\hline 28 & Si & 4933.889 & 0.112 & 46 & 63 \\
\hline 32 & S & 840.993 & 0.347 & 33 & 55 \\
\hline 35 & CI & 1951.14 & 6.33 & 45 & 62 \\
\hline 39 & K & 770.305 & 0.903 & 45 & 62 \\
\hline 40 & Ca & 1942.67 & 0.352 & 45 & 63 \\
\hline 48 & Ti & 1381.745 & 5.18 & 45 & 60 \\
\hline 55 & Mn & 846.754 & 13.1 & 39 & 43 \\
\hline 56 & Fe & 352.347 & 0.273 & 45 & 60 \\
\hline 59 & Co & 229.879 & 7.18 & 38 & 45 \\
\hline 63 & Cu & 202.95 & 0.193 & 9 & 47 \\
\hline 149 & Sm & 333.97 & 4790 & 45 & 58 \\
\hline 157 & Gd & 181.931 & 7200 & 40 & 60 \\
\hline 164 & Dy & 538.609 & 69.2 & 14 & 6 \\
\hline & Totalnumber of samples & 48 & 63 \\
\hline
\end{tabular}

possible to presume these two were added at the time of their production.

Then, the ratio of gamma-ray peak area net count rate in each element to one in the silicon ( $\mathrm{Si}$ ) was calculated, it showed the comparison result which was analyzed a correlation between each element in Table 2 . The characteristics of location was discussed from the pairs of $\mathrm{Gd} / \mathrm{Si}$ and $\mathrm{Sm} / \mathrm{Si}, \mathrm{Co} / \mathrm{Si}$ and $\mathrm{Fe} / \mathrm{Si}, \mathrm{Fe} / \mathrm{Si}$ and $\mathrm{Al} / \mathrm{Si}, \mathrm{K} / \mathrm{Si}$ and
Table 2 Correlation between each element

\begin{tabular}{|c|c|c|c|c|c|c|c|c|c|c|c|c|c|c|c|c|}
\hline & H & $\mathrm{Na}$ & $\mathbf{M g}$ & Al & $\mathbf{S}$ & CI & $\mathbf{K}$ & Ca & $\mathbf{T i}$ & Mn & Fe & Co & Cu & Sm & Gd & Dy \\
\hline $\mathbf{H}$ & & & & & & & & \multirow{7}{*}{\multicolumn{9}{|c|}{$\begin{array}{l}\text { Correlation (correlation factor) } \\
\text { (O) : Strong correlation }(0.8-1.0) \\
O: \text { Considerable correlation }(0.5-0.8) \\
\Delta: \text { Weak correlation }(0.2-0.5) \\
x: \text { No correlation }(0.0 \sim 0.2) \\
- \text { : Evaluation is not made because } \\
\text { the number of detections is quite } \\
\text { few. }\end{array}$}} \\
\hline $\mathbf{N a}$ & $\Delta$ & 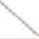 & & & & & & & & & & & & & & \\
\hline Mg & - & - & & & & & & & & & & & & & & \\
\hline Al & (a) & $\Delta$ & - & 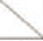 & & & & & & & & & & & & \\
\hline $\mathbf{s}$ & 0 & $\Delta$ & - & $\Delta$ & & & & & & & & & & & & \\
\hline CI & $\Delta$ & $x$ & - & $\Delta$ & $\Delta$ & & & & & & & & & & & \\
\hline $\mathbf{K}$ & $\mathrm{O}$ & $\mathrm{O}$ & - & () & $\Delta$ & $\Delta$ & & & & & & & & & & \\
\hline $\mathrm{Ca}$ & 0 & $x$ & - & $\Delta$ & $\Delta$ & $\Delta$ & $\Delta$ & & & & & & & & & \\
\hline $\mathbf{T i}$ & $\mathrm{O}$ & $\Delta$ & - & $\mathrm{O}$ & $\Delta$ & $\Delta$ & $\mathrm{O}$ & $\Delta$ & & & & & & & & \\
\hline Mn & 0 & $\Delta$ & - & $\mathrm{O}$ & $\Delta$ & $\Delta$ & $\Delta$ & $\Delta$ & 0 & & & & & & & \\
\hline Fe & 0 & $\Delta$ & - & (2) & $\Delta$ & $\Delta$ & 0 & $\Delta$ & $\mathrm{O}$ & 0 & & & & & & \\
\hline \begin{tabular}{|c|} 
Co \\
\end{tabular} & $\mathrm{O}$ & $\Delta$ & - & $\mathrm{O}$ & $\Delta$ & $\Delta$ & $\mathrm{O}$ & $x$ & $\Delta$ & $\mathrm{O}$ & (9) & & & & & \\
\hline $\mathrm{Cu}$ & - & - & - & - & - & - & - & - & - & - & - & - & & & & \\
\hline Sm & 0 & $\Delta$ & - & 0 & $\Delta$ & $\Delta$ & 0 & 0 & 0 & 0 & 0 & 0 & - & & & \\
\hline Gd & 0 & $x$ & - & 0 & $\Delta$ & $\Delta$ & $\Delta$ & 0 & $\Delta$ & 0 & 0 & 0 & - & (1) & & \\
\hline Dy & - & - & - & - & - & - & - & - & - & - & - & - & - & - & - & \\
\hline
\end{tabular}

$\mathrm{Al} / \mathrm{Si}$, that showed particularly strong correlation. As for the classification of the location, sands of Japan and U.S.A. (San Francisco) were added for comparison to the sampling areas of Egypt, Syria, Iran and Iraq.

Since the green body of the faience contains stone and sand as main materials having a lot of quartz $\left(\mathrm{SiO}_{2}\right)$ mixed with a small amount of lime $(\mathrm{CaO})$ and alkali salt $\left(\mathrm{Na}_{2} \mathrm{O}\right.$ or $\mathrm{K}_{2} \mathrm{O}$ ) as glaze, it was analyzed whether there was the characteristics of the age, from the relationship among $\mathrm{Na}, \mathrm{K}$ and $\mathrm{Ca}$. And focusing on the coloration of the blue-green to show a characteristic "color of the life" of the ancient Egyptian faience, it was analyzed whether there was the characteristics of the age, from the relationship between Co and $\mathrm{Cu}$. As for the age, Ptolemaic dynasty (B.C.332-B.C.30) which was the last dynasty of the ancient Egyptian, later Roman period (B.C.31 - A.D.395) and Graeco-Roman period existing over both eras were categorized.

\section{Results and Discussion}

Among the ratio of gamma-ray peak area net count rate to that of silicon ( $\mathrm{Si}$ ) in each element, results having particularly strong correlation are shown in Figs. 2 5 as a function of sand area comparing with those of faience. In every distribution, the correlation was very strong, however, features that could characterize the area were not seen. The distribution was rather dispersed widely. In addition, for $\mathrm{Co} / \mathrm{Si}$ in Fig. 3 and $\mathrm{K} / \mathrm{Si}$ in Fig. 5, increase of the amount of $\mathrm{Co}$ and $\mathrm{K}$ was seen in the distribution of the faience in comparison with that of the sand. It is presumed that these elements were added at the time of the faience production.

The relation of the $\mathrm{K} / \mathrm{Ca}$ and $\mathrm{Na} / \mathrm{Ca}$ ratios for the faience case was shown in Fig. 6 in comparison with the ones of the sand to discuss the characteristics of the age focusing on use of $\mathrm{Na}_{2} \mathrm{O}$ and $\mathrm{K}_{2} \mathrm{O}$ as glaze. In group I which shows higher $\mathrm{K} / \mathrm{Ca}$ ratio, use of $\mathrm{K}_{2} \mathrm{O}$ can be expected because $\mathrm{Na} / \mathrm{Ca}$ ratio is approximately constant though $\mathrm{K} / \mathrm{Ca}$ ratio increases. In group II which shows lower K/Ca ratio, use of $\mathrm{Na}_{2} \mathrm{O}$ can be expected because $\mathrm{K} / \mathrm{Ca}$ ratio is approximately constant 


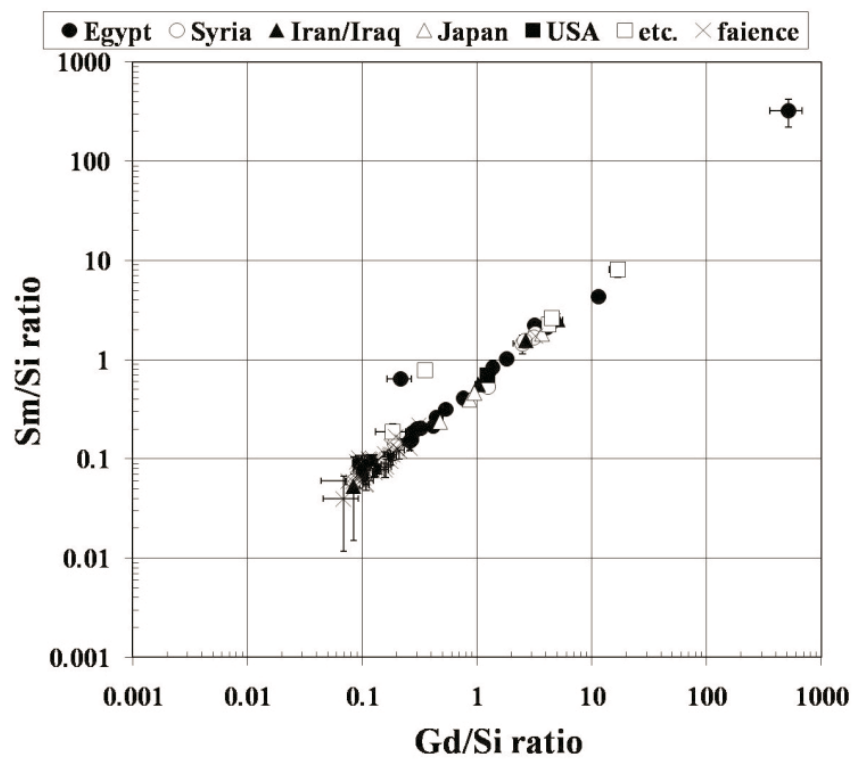

Fig. 2 The relationship between $\mathrm{Gd} / \mathrm{Si}$ ratio and $\mathrm{Sm} / \mathrm{Si}$ ratio

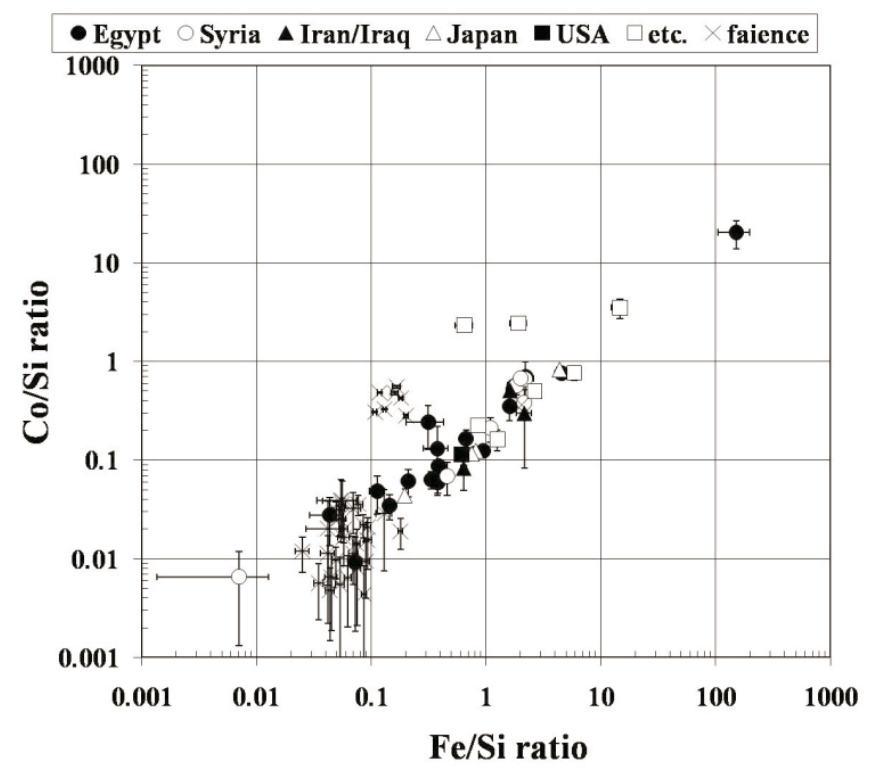

Fig. 3 The relationship between $\mathrm{Fe} / \mathrm{Si}$ ratio and $\mathrm{Co} / \mathrm{Si}$ ratio

though $\mathrm{Na} / \mathrm{Ca}$ ratio increases. It is difficult to find a specific feature on the period for them, however, it is clear that most cases of the faience in the Roman era were found in the group $\Pi$.

Next, the relation between $\mathrm{K} / \mathrm{Na}$ and $\mathrm{Co} / \mathrm{Cu}$ ratios that is known to be a coloration source of blue-green is shown in the Fig. 7. Here, the correlated distribution is divided into group III which shows higher $\mathrm{Co} / \mathrm{Cu}$ ratio and group IV which shows lower $\mathrm{Co} / \mathrm{Cu}$ ratio. One can estimate that $\mathrm{Co}$ ingredient was added for the former and that $\mathrm{Cu}$ ingredient was added for the latter at the time of their production. However, the age characteristics cannot be found in neither group. Nevertheless, the number of the faience cases included in group IV is considerably large. In addition, there exist two groups, one of which is a group where only the $\mathrm{Cu}$ was detected (Co not detected) and the other of which is a group where only the $\mathrm{Co}$ was detected ( $\mathrm{Cu}$ not detected).

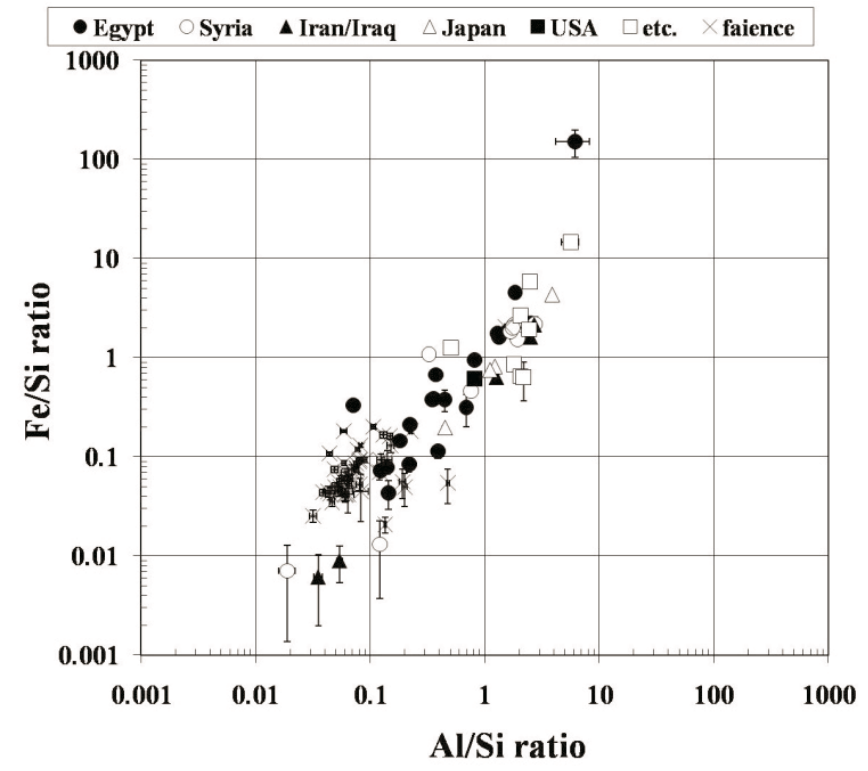

Fig. 4 The relationship between $\mathrm{Al} / \mathrm{Si}$ ratio and $\mathrm{Fe} / \mathrm{Si}$ ratio

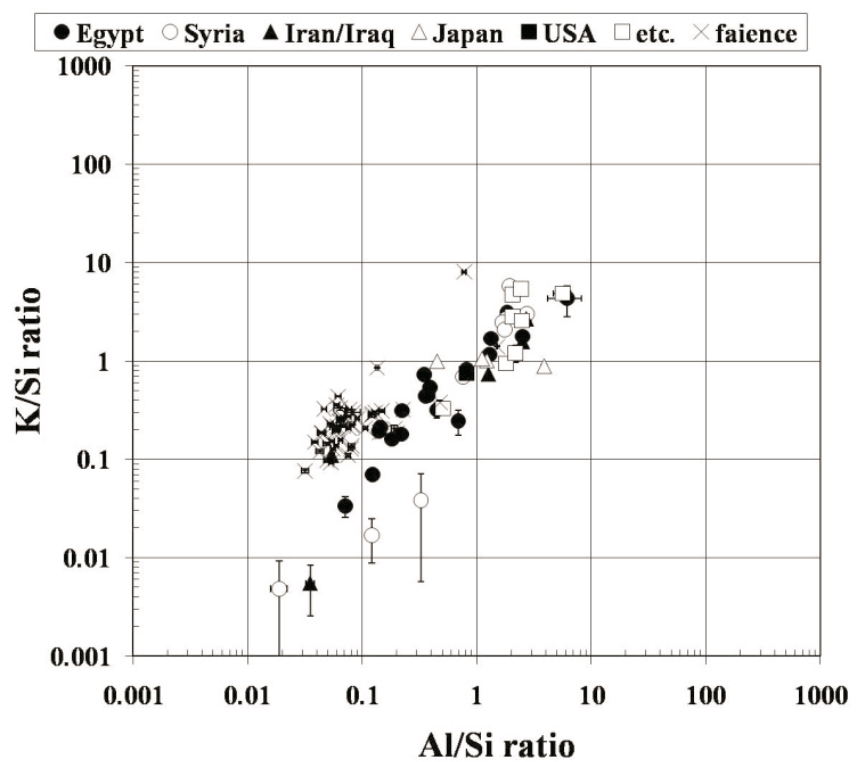

Fig. 5 The relationship between $\mathrm{Al} / \mathrm{Si}$ ratio and $\mathrm{K} / \mathrm{Si}$ ratio

However, the characteristics of the age cannot be found similarly.

Also, Fig. 8 shows relations between the $\mathrm{Ca} / \mathrm{Gd}$ and $\mathrm{Co} / \mathrm{Cu}$ ratios. Attention is paid to two groups. One is group $\mathrm{V}$ of Graeco-Roman period (the Ptolemaic dynasty) where the history was old. The other is group VI of Roman period after Graeco-Roman period. As the times change to Roman period, productions of the faience including a lot of $\mathrm{Ca}$ ingredient is thought to be enhanced. This is due to the fact that Akoris was located in the limestone plateau, in which a large amount of high quality limestone was yielded. Akoris was regarded as an important building stones supply place in Roman period. It can be estimated that such a trend could affect the change in the elemental composition in the faience.

\section{Conclusion}




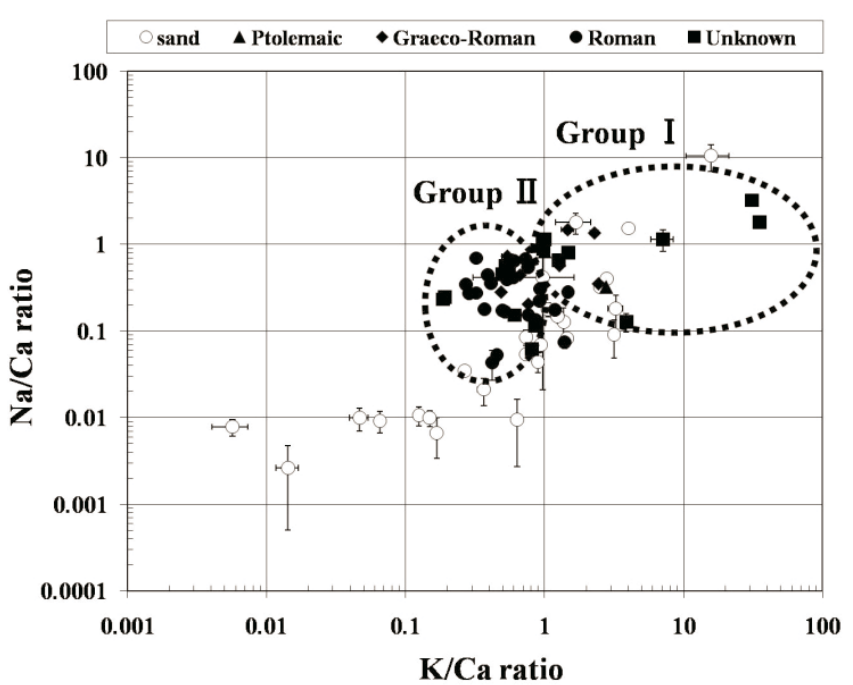

Fig. 6 The relationship between $\mathrm{K} / \mathrm{Ca}$ ratio and $\mathrm{Na} / \mathrm{Ca}$ ratio

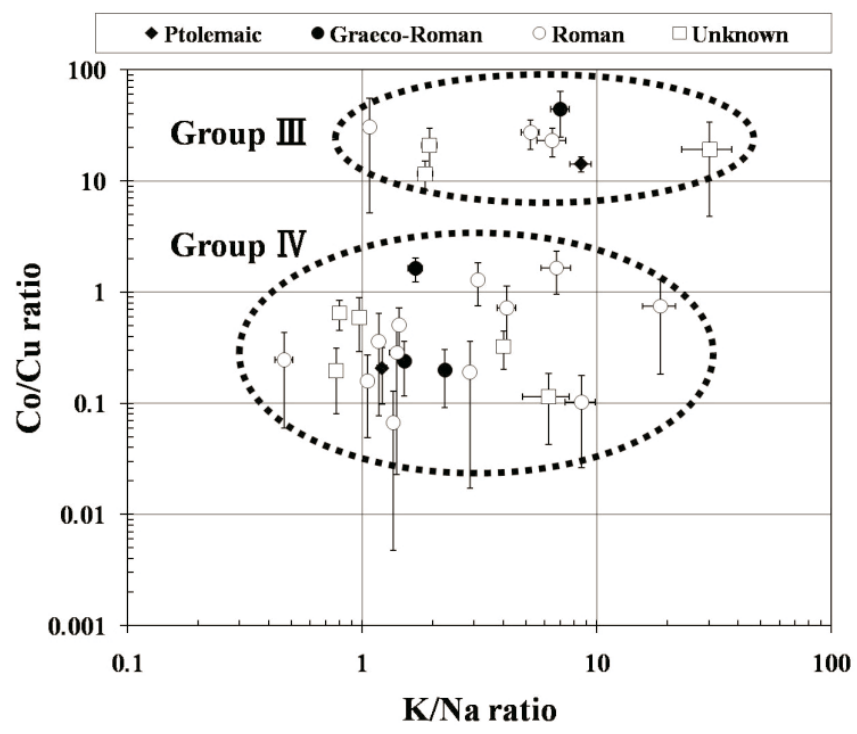

Fig. 7 The relationship between $\mathrm{K} / \mathrm{Na}$ ratio and $\mathrm{Co} / \mathrm{Cu}$ ratio

We have compared the elemental compositions between faience excavated from Akoris and sands of Egypt and neighboring West Asia districts to examine possibility of correlation. Correlation was seen between many elements, however, it was not able to find the characteristics of location. In addition, careful attention was paid to the relationship among $\mathrm{Na}, \mathrm{K}$ and $\mathrm{Ca}$, in order to examine whether there was the characteristics of age for use of the glaze. Focusing on the relationship between $\mathrm{Co}$ and $\mathrm{Cu}$ which were a coloration element to color in blue-green, that is, known to be a characteristic "color of the life" of the ancient Egyptian faience, it was analyzed whether there was the characteristics of age. However, but the characteristics of age could not be found significantly. Nevertheless, for the change of $\mathrm{Ca}$ ingredient, results to support the historical fact in the characteristics of both age and location were seen. In conclusion, it is necessary to systematically examine more historical samples to totally find out the characteristics of the

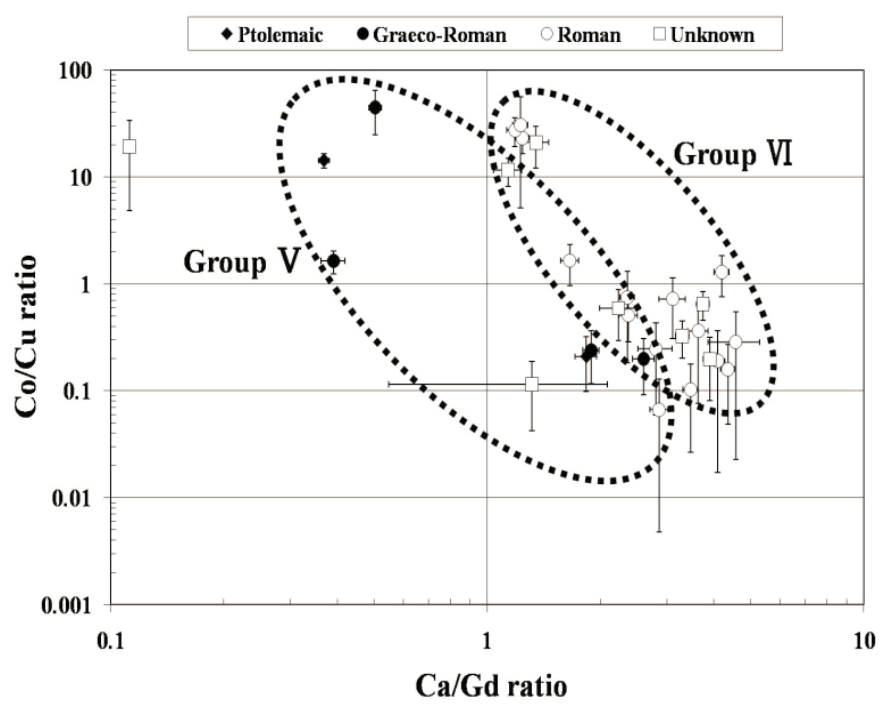

Fig. 8 The relationship between $\mathrm{Ca} / \mathrm{Gd}$ ratio and $\mathrm{Co} / \mathrm{Cu}$ ratio

age and location of the excavated relics.

\section{References}

1) M. D. Glascock, "The status of activation analysis in archaeology and geochemistry," J. Radioanal. Nucl. Chem., 244[3], 537-541 (2000).

2) K. T. Biro, "Non-destructive research in archaeology," J. Radioanal. Nucl. Chem., 268[2], 235-240 (2005).

3) H. Nakahara, Y. Oura, K. Sueki, M. Ebihara, W. Sato, Sk. A. Latif, T. Tomizawa, S.Enomoto, C. Yonezawa and Y. Ito, "Some basic studies on non-destructive elemental analysis of bulky samples by PGAA," J. Radioanal. Nucl. Chem., 244[2], 405-411 (2000).

4) K. Yamahana, "Ancient Egyptian glass vessels from the New Kingdom: a comparative analysis with Roman glass," Orient, 44[1], 25-41 (2001), [in Japanese].

5) K. Yamahana, "Synchrotron radiation analysis on ancient Egyptian vitreous materials," Proc. of the $25^{\text {th }}$ Linear Accelerator Meeting in Japan, Himeji, Japan, July 12-14, 2000, 13C-01 (2000).

6) Zs. Kasztovszky, Zs. Revay, T. Belgya and G. L. Molnar, "Nondestructive analysis of metals by PGAA at the Budapest Research Reactor," J. Radioanal. Nucl. Chem., 244[2], 379-382 (2000).

7) R. G. V. Hancock, J. McKechnie, S. Aufreiter, K. Karklins, M.Kapches, M. Sempowski, J.-F. Moreau and I.Kenyon, "Non-destructive analysis of European cobalt blue glass trade beads," J. Radioanal. Nucl. Chem., 244[3], 567-573 (2000).

8) A. El-Taher, "Rare-earth elements in Egyptian granite by instrumental neutron activation analysis," Appl. Radiat. Isot. 65[4], 458-464 (2007).

9) G. Szakmany and Z. Kasztovszky, "Prompt gamma activation analysis, a new method in the archaeological study of polished stone tools and their raw materials," Eur. J. Miner. 16[2], 285-295 (2004).

10) Gabor L. Molnar, "Handbook of prompt gamma activation analysis with neutron beams," Kluwer Academic Publishers (2004). 